Mila Desouzart de Aquino Viana

O que anseiam os jovens trabalhadores? Valores e expectativas da geração $Y$ acerca do trabalho

Dissertação de Mestrado

Dissertação apresentada ao Programa de Pósgraduação em Administração de Empresas da PUCRio como requisito parcial para obtenção do título de Mestre em Administração de Empresas

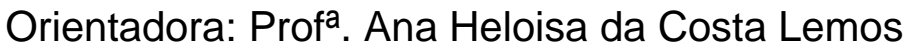

Rio de Janeiro

Abril de 2011. 
Mila Desouzart de Aquino Viana

\title{
O que anseiam os jovens trabalhadores? Valores e expectativas da Geração Y acerca do trabalho
}

Dissertação apresentada como requisito parcial para obtenção do grau de Mestre pelo Programa de Pósgraduação em Administração de Empresas da PUC-Rio. Aprovada pela Comissão Examinadora abaixo assinada.

\author{
Profa. Ana Heloisa da Costa Lemos \\ Orientadora \\ Departamento de Administração - PUC-Rio
}

Prof. Jorge Manoel Teixeira Carneiro Departamento de Administração - PUC-Rio

Prof ${ }^{a}$. Flavia de Souza Costa Neves Cavazotte

IBMEC - Rio

Profa. Mônica Herz

Vice-Decana de Pós-Graduação do CCS

Rio de Janeiro, 1 de abril de 2011 
Todos os direitos reservados. É proibida a reprodução total ou parcial do trabalho sem autorização da universidade, da autora e da orientadora.

\section{Mila Desouzart de Aquino Viana}

Graduou-se em Administração de Empresas na UERJ (Universidade do Estado do Rio de Janeiro) em 1995. Cursou MBA - IAG Management no período de 2006 a 2007 na PUC-Rio. Trabalha a mais de quinze anos com gestão financeira e também na área de consultoria e auditoria. Atualmente trabalha como Coordenadora de Incubadora no Instituto Gênesis da PUC-Rio e é sócia da empresa de consultoria de gestão de negócios OD Consultoria Planejamento e Estratégia de Mercado Ltda.

Ficha Catalográfica

Viana, Mila Desouzart de Aquino

O que anseiam os jovens trabalhadores? Valores e expectativas da geração $\mathrm{Y}$ acerca do trabalho / Mila Desouzart de Aquino Viana ; orientadora: Ana Heloisa da Costa Lemos. - 2011.

106 f. : il. (color.) ; $30 \mathrm{~cm}$

Dissertação (mestrado)-Pontifícia Universidade Católica do Rio de Janeiro, Departamento de Administração, 2011.

Inclui bibliografia

1. Administração - Teses. 2. Geração Y. 3. Comprometimento. 4. Valores. 5. Escolha do emprego. I. Lemos, Ana Heloisa da Costa. II. Pontifícia Universidade Católica do Rio de Janeiro. Departamento de Administração. III. Título. 
A Deus em primeiro lugar.

Ao meu marido e meus filhos amados pelo apoio e carinho. Ao eterno Professor José Roberto Gomes da Silva, que foi um grande incentivador e que sempre estará na minha memória. 


\section{Agradecimentos}

Agradeço em primeiro lugar a Deus, sem ele nada seria possível. Agradeço ao Pai Maior pela oportunidade e por eu ter tido todas as condições para enfrentar este grande desafio.

Ao meu marido, meu melhor amigo e companheiro cujo apoio, carinho, paciência e força foram fundamentais para a realização deste trabalho.

Aos meus filhos, razões da minha vida, pela compreensão, apoio, paciência e por abrirem mão, muitas vezes, do tempo que passamos juntos.

A minha mãe e meus dois pais por terem me ensinado a ser perseverante, por todo o apoio, carinho e incentivos recebidos.

Aos meus sogros pela confiança, carinho e apoio.

Agradeço a força de todos os meus demais familiares que sempre traziam palavras de alento nas horas difíceis.

A Maria Madalena Caetano, minha fiel escudeira, que cuidou de mim e dos meus filhos com muito carinho durante a realização deste trabalho.

A querida Profa. e orientadora Ana Heloisa da Costa Lemos, cujo apoio, confiança e orientação foram fundamentais para a realização da presente pesquisa.

A todos os meus queridos amigos que me apoiaram incondicionalmente e em especial a Nadine Lopes, Maria e Marcelo Torres, Lygia Magacho, Mila Schiavo, Priscila Castro e Eduardo Santini, cujo apoio e incentivo foram primordiais nos momentos de cansaço e desânimo. 


\section{Resumo}

Viana, Mila Desouzart de Aquino. Lemos, Ana Heloisa da Costa. O que anseiam os jovens trabalhadores? Valores e expectativas da geração $\mathbf{Y}$ acerca do trabalho. Rio de Janeiro, 2010. 106p. Dissertação de Mestrado Departamento de Administração, Pontifícia Universidade Católica do Rio de Janeiro.

Esta dissertação teve como objetivo a análise dos valores e dos atributos relacionados à escolha do emprego de uma amostra de representantes da geração Y, estudantes de Administração de Empresas de uma Universidade no Rio de Janeiro. Este grupo geracional possui características distintas e peculiares em relação às gerações antecessoras, o que se traduz na necessidade das organizações em lidarem com os desafios de administrar a convivência de diversas gerações em um mesmo ambiente organizacional, bem como o de reter e comprometer estes novos profissionais. A metodologia adotada foi de natureza quantitativa, tendo sido utilizado um questionário fechado baseado na metodologia de Shalom $\mathrm{H}$. Schwartz (1992). As literaturas sobre diferenças geracionais, geração Y, comprometimento, escolha do trabalho e valores serviram de pano de fundo para a interpretação dos dados obtidos. O estudo traçou, a partir da amostra levantada, um retrato dos valores e desejos destes jovens, podendo contribuir para o entendimento das aspirações e valores desta nova força de trabalho. Os principais resultados da pesquisa sugerem que algumas das características dos representantes da geração $\mathrm{Y}$ abordadas pela literatura foram confirmadas para a amostra pesquisada. Todavia, há divergências com relação a outras características, o que reforça a relevância em realizar pesquisas que aprofundem o conhecimento sobre esta geração.

\section{Palavras-chave}

Geração Y; comprometimento; valores; escolha do emprego; 


\section{Abstract}

Viana, Mila Desouzart de Aquino. Lemos, Ana Heloisa da Costa (Advisor). What are the aspirations of young workers? Values and expectations of generation $\mathbf{Y}$ about the work. Rio de Janeiro, 2010. 106p. MSc. Dissertation - Departamento de Administração, Pontifícia Universidade Católica do Rio de Janeiro.

The objective of this paper is to assess values and attributes related to the job choice of a sample of representatives of generation $\mathrm{Y}$, business administration students at a university in Rio de Janeiro. This generation has distinct and peculiar characteristics when compared to those of previous generations, which means organizations need to deal with the challenges of handling the co-existence of several generations in the same work environment, as well as retain them and get them to commit themselves to these organizations. The nature of the methodology adopted was quantitative, through the use of a closed questionnaire based on Shalom H. Schwartz's methodology. The existing literature on generational differences, generation $\mathrm{Y}$, commitment, job choice and values was used as the background for the interpretation of the data obtained. The data gathered were interpreted with base on the existing literature on generational differences, generation Y, commitment, job choice and values. This study maps out the values and aspirations of this generation, and it aims at contributing to a better understanding of the aspirations and values of this new work force. The main results of this research suggest that some of the characteristics of the representatives of generation $\mathrm{Y}$ addressed by literature have been confirmed for the sample researched. Nevertheless, there are discrepancies as regards other characteristics, which reinforces the relevance to conduct research in order to deepen knowledge on this generation on the matter.

\section{Keywords}

Generation Y; commitment; values; job choice 


\section{Sumário}

$\begin{array}{ll}\text { 1. Introdução } & 14\end{array}$

$\begin{array}{ll}\text { 1.1. Problema de Pesquisa } & 17\end{array}$

1.2. Objetivo Principal 17

1.3. Relevância 18

1.4. Delimitação do Estudo 19

2. Referencial Teórico 20

2.1. O Conceito de Geração 20

2.1.1. Geração Baby Boomers 22

2.1.2. Geração X 23

2.1.3. Geração Milênio ou Geração $Y$

2.1.3.1. Educação dos Jovens da Geração $Y \quad 24$

2.1.3.2. Características Comportamentais da Geração $Y \quad 24$

2.1.3.3. Anseios da Geração $Y \quad 27$

2.1.3.4. Questões Valorizadas pelos Jovens da Geração $Y \quad 28$

2.1.3.5. Relação da Geração Y com as Organizações 28

2.2. O Comprometimento Organizacional 30

2.3. A Escolha do Trabalho 33

2.4. A Questão dos Valores 34

2.4.1. Teorias sobre Valores $\quad 35$

2.4.2. Pesquisa sobre Valores de Schwartz 38

3. Dados e Métodos do Estudo 49

3.1. Objetivo da Pesquisa 49

3.2. Definição de Amostra para a Pesquisa 50

3.3. Procedimentos de Coleta e Registro de Dados 52

3.4. Procedimentos para Análise e Tratamento dos Dados 52

3.4.1. Procedimentos para Análise de Frequência dos Dados 52

3.4.2. Procedimentos para Análise de Cluster 54

3.5. Limitações do Método 58 
4. Análise dos Resultados $\quad 59$

4.1. Introdução

4.2. Mapeamento dos Tipos Motivacionais de Valores dos "Yrs" 59

4.2.1. Tipo Motivacional de Valores "Auto-Suficiência" 60

4.2.2. Tipo Motivacional de Valores “Estimulação” 61

4.2.3. Tipo Motivacional de Valores "Hedonismo" 62

4.2.4. Tipo Motivacional de Valores "Realização" 63

4.2.5. Tipo Motivacional de Valores "Poder" 64

4.2.6. Tipo Motivacional de Valores "Segurança" 65

4.2.7. Tipo Motivacional de Valores "Conformidade" 67

4.2.8. Tipo Motivacional de Valores "Tradição" 68

4.2.9. Tipo Motivacional de Valores "Benevolência" 69

4.2.10. Tipo Motivacional de Valores "Universalismo" 71

4.3. Análise das Preferências em Relação a Atributos do Trabalho 72

4.4. Análise de Cluster 74

4.4.1. Análise de Cluster por Z-Score: Valores dos "Yrs" 74

4.4.2. Análise do Atributo do Trabalho por Cluster 77

5. Considerações Finais 85

5.1. Sugestões para Futuras Pesquisas 91

6. Referências Bibliográficas 93

Apêndice I - Questionário Utilizado na Pesquisa 97

$\begin{array}{ll}\text { Anexo I - Resultados dos Testes Estatísticos } & 102\end{array}$ 


\section{Lista de quadros}

Quadro 1: Características dos grupos geracionais 


\section{Lista de figuras}

Figura 1: Estrutura de valores Schwartz (1994) 


\section{Lista de tabelas}

Tabela 1: Associação de valores com tipos motivacionais de valores

Tabela 2: Tipos de trabalhos informados pelos pesquisados

Tabela 3: Intervalos para análise de freqüência dos tipos motivacionais de valores

Tabela 4: Resultado final análise de cluster (Z-Score) 


\section{Lista de gráficos}

Gráfico 1: Distribuição de frequência dos graus de importância para o tipo motivacional de valores "Auto-Suficiência"

Gráfico 2: Distribuição de frequência dos graus de importância para o tipo motivacional de valores "Estimulação"

Gráfico 3: Distribuição de frequência dos graus de importância para o tipo motivacional de valores - "Hedonismo"

Gráfico 4: Distribuição de frequência dos graus de importância para o tipo motivacional de valores "Realização"

Gráfico 5: Distribuição de frequência dos graus de importância para o tipo motivacional de valores "Poder"

Gráfico 6: Distribuição de frequência dos graus de importância para o tipo motivacional de valores "Segurança"

Gráfico 7: Distribuição de frequência dos graus de importância para o tipo motivacional de valores "Conformidade"

Gráfico 8: Distribuição de frequência dos graus de importância para o tipo motivacional de valores "Tradição"

Gráfico 9: Distribuição de frequência dos graus de importância para o tipo motivacional de valores "Benevolência"

Gráfico 10: Distribuição de frequência dos graus de importância para o tipo motivacional de valores "Universalismo"

Gráfico 11: Preferências da amostra em relação a atributos

do trabalho

Gráfico 12: Análise de Cluster (Z-Score)

Gráfico 13: Atributos do trabalho considerados mais Importantes no cluster 1

Gráfico 14: Atributos do trabalho considerados mais Importantes no cluster 2

Gráfico 15: Atributos do trabalho considerados mais Importantes no cluster 3 